\title{
Prescripciones dietéticas para las élites rectoras del reino de Navarra durante la primera mitad del siglo XVI: los casos de Juan Rena y Juan de Alarcón
}

\author{
Fernando Serrano Larráyoz (*) \\ ${ }^{*}$ ) Departamento de Cirugía y Ciencias Médicas y Sociales, Universidad de Alcalá. Alcalá de \\ Henares, España. \\ fernando.serranol@uah.es
}

Dynamis

[0211-9536] 2014; $34(1): 169-192$

Fecha de recepción: 8 de noviembre de 2012

http://dx.doi.org/10.4321/S0211-95362014000100009

Fecha de aceptación: 20 de junio de 2013

SUMARIO: 1.-Introducción. 2.-Prescripciones dietéticas para micer Juan Rena (ca. 1480-1539). 3.-Prescripciones dietéticas para Juan de Alarcón († 1551). 4.-Reflexiones finales. Apéndice documental.

RESUMEN: Se analizan y transcriben cuatro prescripciones dietéticas para el clérigo de origen veneciano Juan Rena y su servidor Juan de Alarcón, fechadas en la primera mitad del siglo XVI y conservadas en el Archivo General de Navarra. Muestran el interés de médicos y pacientes por la dietética, entendida como el conjunto de medidas higiénico-sanitarias basadas en las res naturales y res non naturales galénicas. Estas cuatro prescripciones están estrechamente relacionadas con un género de literatura médica (regímenes de salud ad personam o consilia) hasta ahora poco estudiado para la España renacentista. Los casos que aquí se exponen evidencian el aprecio entre las clases altas por la posesión de recursos terapéuticos adaptados a las necesidades individuales, que se copiaban y recopilaban para un uso personal.

PALABRAS CLAVE: prescripciones dietéticas, Juan Rena, Juan de Alarcón, Navarra, siglo XVI.

KEY WORDS: dietary prescriptions, Juan Rena, Juan de Alarcón, Navarre, 16th century.

\section{Introducción $(*)$}

La vigencia de los regimina sanitatis durante el Renacimiento resulta evidente en la literatura médica hispana por la cantidad de tratados publicados a lo

(*) Este trabajo ha sido realizado en el marco del proyecto de investigación FFI2011-29117-C02-01 concedido por el Ministerio de Ciencia e Innovación (ahora Ministerio de Economía y Competitividad). 
largo del siglo XVI tanto en latín como en romance (castellano o catalán) y la proliferación de reediciones de antiguos textos medievales ${ }^{1}$. Una literatura cuyos antecedentes hay que buscarlos en la tradición galénica medieval, que puso especial énfasis en las denominadas sex res non naturales, factores que aunque no constituían la naturaleza individual de cada persona, como las res naturales, contribuían a un mejor mantenimiento de la salud. La difusión de estos conocimientos a través de las lenguas vernáculas refleja en buena medida ciertas actitudes de las élites de la sociedad de la época, en las que el galenismo siguió vigente incluso hasta el siglo XVII ${ }^{2}$.

1. Sobre la importancia de las lenguas vernáculas en este tipo de obras, véase Gutiérrez Rodilla, Bertha. La adecuación lingüística al destinatario en los textos médicos instructivos y de divulgación del Renacimiento castellano. Res Diachronicae. 2009; 7: 37-46 (39). Respecto a su difusión en catalán, véase Cifuentes i Comamala, Lluís. La ciencia en català a l'Edat Mitjana i el Renaixement. Barcelona-Palma de Mallorca: Universitat de Barcelona-Universitat de les Illes Balears; 2006 (2. a edición), p. 96-105. Al catalán (1499) y al castellano (1567) fue traducido Il Perché o Liber de homine (1474), a la vez régimen de salud y tratado de fisiognomía, del médico boloñés Girolamo Manfredi, cuya primera parte, dedicada a la conservación de la salud, corresponde a un régimen de sanidad dividido en siete capítulos. Sobre esta última cuestión, véase Carré, Antònia; Cifuentes, Lluís. Éxito y difusión de la literatura de Problemas en la Castilla del siglo XVI: la traducción castellana de II Perché de Girolamo Manfredi (Zaragoza, 1567). Asclepio. 2006; 58 (1): 149-196 (171-172). Los textos impresos también podían convertirse en colecciones abiertas, como muestra una copia del régimen de sanidad salernitano publicado en Lyon en 1516 — Regimen sanitatis Salerni: accurate castigatum adiecta tabula in calce libri hactenus non impressa, Lyon, Jacobum Myt expensis Bartholomei Trot, 1516 - y custodiada en la Biblioteca General de Navarra. «Al final del texto latino, anotado por una mano coetánea, le sigue una lista de más de 40 recetas escritas por dos manos anónimas en latín, castellano y catalán, una colección que completa los consejos domésticos ofrecidos por el régimen de sanidad para el mantenimiento de la salud y prevención de la enfermedad». Cabré, Montserrat. Los consejos para hermosear («libros» I-III) en el Regalo de la vida humana de Juan Vallés. In: Serrano Larráyoz, Fernando, coord. [Juan Vallés] Regalo de la vida humana. Pamplona-Viena: Gobierno de Navarra-Österreichische Nationalbibliothek; 2008, vol. 2, p. 171-202 (180).

2. Una visión de conjunto sobre la vernacularización y la continuidad de la tradición de la ciencia del medievo durante el Renacimiento, véase en Cifuentes i Comamala, Lluís. La ciencia en vulgar y las élites laicas, de la Edad Media al Renacimiento. In: Serrano Larráyoz, n. 1, p.123148. Una breve aproximación respecto algunas de las obras renacentistas en castellano vinculadas a los regimina sanitatis, en López Piñero, José María. Los orígenes de los estudios sobre la salud pública en la España renacentista. Revista Española Salud Pública. 2006; 80 (5): 445-456 (449-450). La influencia de esta literatura llegó hasta el siglo XVII, como la versión castellana del Regimen sanitatis ad regem Aragonum de Arnau de Vilanova (compuesto hacia 1305) publicada en Barcelona (1606) por Jerónimo de Mondragón, cuyo título es Maravilloso regimiento i orden de vivir, para tener salud, i alargar la vida; que compuso, el doctisimo Medico Arnaldo de Vilanova, para el serenisimo Rei de Aragon, don Jaime el Segundo: sacado de vn libro latino de mano mui antiguo, traslado del mesmo original del Autor; i puesto en esta lengua, por el 
En este trabajo presentamos cuatro prescripciones de carácter dietético de la primera mitad del siglo XVI, conservadas en el Archivo General de Navarra. Se trata de documentos valiosos debido a la escasez de ejemplos conocidos de este tipo de fuentes para el ámbito hispano renacentista y que muestran el interés de médicos y pacientes por la dietética, entendiéndola como régimen general de la vida de un individuo con el fin de mantener o lograr el restablecimiento de la salud. La medicina individualizada que se practicaba en el medievo y en el primer Renacimiento requería el análisis de la complexión particular del órgano que se buscaba tratar, lo que implicaba la existencia de «muchas saludes diferentes» en un mismo individuo. Así, las distintas complexiones de cada persona justificaban a su vez la existencia de diferentes regímenes de salud, «reglas de vida individuales hechas a la medida del sujeto que las utiliza, con el fin de mantenerle sano» ${ }^{3}$. Los documentos que aquí transcribimos son ejemplo de la práctica de esta medicina personalizada, adaptada a las necesidades de cada paciente.

Resulta difícil encuadrar los cuatro textos navarros en categorías ficticias, sobre todo en un periodo de transformaciones como el siglo XVI. La diversidad en la expresión formal de estos tratamientos individualizados hace difícil adscribirlos al género de los regimina sanitatis ${ }^{4}$, pues mientras los regimina son textos doctrinales amplios que hacen un recorrido

Licenciado Hieronymo de Mondragón: porque de tan singular Obra, pueda gozar todo el mundo (1609) (Cruz Cruz, Juan. Dietética medieval. Apéndice con la versión castellana del «Régimen de salud» de Arnaldo de Vilanova. Huesca: La Val de Onsera; 1997, p. 295-296).

3. Gil-Sotres, Pedro. Introducción. In: García Ballester, Luis; McVaugh, Michael R.; Gil-Sotres, Pedro; Paniagua, Juan A. eds. [Arnaldi de Villanova] Regimen sanitatis ad regem Aragonum. En: García Ballester, Luis; McVaugh, Michael R.; Gil-Sotres, Pedro; Paniagua, Juan A. eds. Arnaldi de Villanova Opera Medica Omnia. Vol. X.1. Barcelona: Universitat de Barcelona-Fundació Noguera; 1996, p. 471-885 (478). Sobre la proliferación de los textos de uso individual en el siglo XVI, puede verse también en Solomon, Michael. Fictions of well-being: sickly readers and vernacular medical writing in late medieval and early modern Spain. Philadel phia-Oxford: University of Pennsylvania Press; 2010. Para el ámbito italiano véase Cavallo, Sandra. Secrets to healthy living: The revival of the preventive paradigm in late Renaissance Italy. In: Leong, Elaine; Rankin, Alisha, eds. Secrets and knowledge in medicine and science, 1500-1800. Farnham-Burlington: Ashgate; 2011, p. 191-212 (196-200).

4. Con la denominación de «regimiento» es aludido uno de ellos (Apéndice documental, n. ${ }^{\circ}$ 2). Durante el medievo y el periodo renacentista la dietética forma parte de la enseñanza de la medicina práctica junto con la farmacopea y la cirugía para el tratamiento de las enfermedades. El término latino más usado para definirla era diaeta, un término con doble sentido. En sentido estricto hacía referencia a la comida y la bebida, aunque en sentido amplio se refería a las aludidas al inicio del estudio como «cosas no naturales». A diferencia de la farmacopea o de la cirugía la dieta no solo se utilizaba como cura sino también como medio 
completo y ordenado por las 'seis cosas no naturales', los documentos que aquí presentamos constituyen un conjunto de recomendaciones dietéticas, pensadas para tratar una enfermedad concreta de un individuo. Por ello, pueden considerarse más próximos a los consilia que a los regimina sanitatis. Esta relación resulta evidente en tres de los casos estudiados, a pesar de que su estructura no responda totalmente a lo que se consideran las características clásicas de este género: textos cortos, generalmente escritos según el modelo epistolar y divididos habitualmente en tres apartados, que exponen en primer lugar el casus, seguido de una dieta consistente en la elaboración de recomendaciones de naturaleza higiénica - con una sección dedicada a los alimentos generalmente bastante desarrollada-, y finalmente, una cura basada en una farmacopea en particular ${ }^{5}$. Si los consilia forman un género académico estructurado y consistente, las prescripciones que aquí presentamos no responden formalmente a esa pauta pero comparten con los consilia el objetivo de ofrecer un conjunto de recomendaciones médicas adaptadas específicamente a las características de un paciente.

para prevenir la enfermedad y conservar la salud. Nicoud, Marilyn. La dietética medievale: testi e lettori. Minerva. 2010; 23: 15-34 (16).

5. Nicoud, n. 4, p. 18. Para la evolución de los consilia médicos, véase Nicoud, Marilyn. Les régimes de santé au Moyen Âge: naissance et diffusión d'une écriture médicale (XIIIe-XVe siècle). Vol. I. Rome: École Française de Rome; 2007, p. 314-336. De finales de la Edad Media, en el ámbito hispano, conozco el consilium médico de un tal licenciado Antonio, médico del duque de Bretaña, el cual se desplazó a Vitoria para tratar a García Álvarez de Toledo († 1480) — primer duque de Alba - (García Ballester, Luis García. La búsqueda de la salud. Sanadores y enfermos en la España medieval. Barcelona: Península, 2001, p. 357-358) y un magnífico ejemplo, muy semejante a los documentos navarros, de origen catalán, del que se desconoce el destinatario y el médico se puede inducir sin total seguridad de los papeles que hay alrededor: «lhesus. - Primo, vos guordau de pa alís e mal cuyt e calent; de vi agre, ni fort ni agut; de tota carn vella, ni grossa ni en ast - la demés en olla jove, e grassa; de formatge, nous, castanyes, codonys, nesples; de totes coses estíptiques e caldes; de allada, de pebrada, de peix, especialment salat o bestinal. De les coses demunt vedades podeu menjar poch e a tart. — Los remeys. — Beureu alguns matins aquestes coses següents: licor d'ordi ab let d'amenles e sucre; let de amenles ab gra de carabasses, melons, cogombres e semblant; dragagant, let de somera, let de cabra, e sobretot lo serigot, que val més; aygua de indívia o de licsons, stil.lades, de seba blancha, tota hora ab sucre, adés una, adés altre. - Les viandes. - Tota carn grassa e carabasses, letugues, spinachs, bledes, borratges, ortigues ortolanes, fonoll marí e semblants. Ítem, si voleu fer axarob, recipe rel de fonoll, de juyvert, de gram, pentafilon (que és peucrist), ciurons negres (quatre o sinch), figues blanques, pances. Tot bollit ab ayga de font, e beureu d'aquella aygua de matí un gotet, e de vespre, ab sucre. E si.n voleu fer axarob, com l'aygua sia colada e samada, meteu-hi sucre e feu-ne exerob. A part de fora, ajau draps prims banyats ab aygaròs, o de plantatge o de morella vera» (Arxiu Històric de la Ciutat de Barcelona (=AHCB), Fons notarial, IX.2, carp. 5, en Sciència.cat DB, manid $110<$ http://www.sciencia.cat/db/scienciacat-db.htm>). 
De hecho, se ha señalado como junto a la difusión impresa de los géneros médicos tradicionales para el mantenimiento de la salud, proliferaron en este periodo regímenes de salud, recetarios y otros escritos similares adaptados e individualizados por los propios usuarios ${ }^{6}$. En este sentido, es de resaltar que uno de los cuatro documentos transcritos esté escrito por el propio paciente, Juan Rena, quien pudo basarse en algún 'Régimen de salud', y recoger solo aquello que a él le interesaba para alivio de su propia dolencia.

Las cuatro prescripciones dietéticas se conservan en el Archivo General de Navarra y salvo en uno de los casos, no consta en ellos fecha alguna. No obstante, atendiendo a su contenido, a sus vinculaciones con otros textos y a los personajes a ellos vinculados se ha podido sugerir una cronología aproximada. Las dos más antiguas son las destinadas a Juan Rena, fechadas en 1524 y hacia 1528; las dos posteriores fueron prescritas a Juan de Alarcón, su servidor.

\section{Prescripciones dietéticas para micer Juan Rena (ca. 1480-1539)}

Una característica a destacar de las prescripciones dietéticas para Juan Rena es que la más antigua, además de ser la única fechada - mayo de 1524-, responde a unas notas escritas por él mismo. El propio enfermo establece cronológicamente los pasos a adoptar en todo lo relacionado con la ingesta de alimentos, la toma de medicinas, los baños y los masajes que debían aplicarse. No resultaría extraño que además de contar con el consejo de algún médico, para su elaboración hubiera utilizado un Regimen sanitatis que encontramos inventariado en su casa de Pamplona en $1525^{7}$. La segunda dieta, elaborada hacia 1528, fue redactada sin duda alguna por un médico. Su estructura es diferente a la anterior, poniendo especial énfasis en los alimentos que Rena debe o no consumir para pasar a prescribir ciertos compuestos medicamentosos. Si el primer texto finaliza con la receta

6. Sobre algunas de estas cuestiones, véase Cabré, Montserrat. Keeping beauty secrets in early modern Iberia. In: Leong, Elaine; Rankin, Alisha, eds, n. 3, p. 167-190 (169-173).

7. Junto al Regimine sanitatis destaca también un libro de cozina (Archivo General de Navarra (=AGN), Archivos Particulares-Rena, caj. 105, n. ${ }^{0}$ 14-1). Resulta interesante destacar ambos ejemplares de un total de medio centenar, la mayoría de materia religiosa, que se recogen ese año (1525). Otra mano añade al libro Postillas de Nicolás de Lira la anotación de antidotariu[m]; un error, quizás, al confundirlo con el salernitano Antidotarium Nicolai cuando en realidad es una obra teológica. 
de un ungüento que Rena debe utilizar, el segundo recoge toda una serie de simples medicinales que tenía que tomar. No obstante, es importante señalar que la redacción de la receta del ungüento, así como la relación de los simples medicinales de la segunda prescripción, están escritas por manos diferentes respecto al cuerpo general de cada dieta, lo que sugeriría la implicación de diversas personas en su elaboración.

Veneciano de origen, Juan Rena nació hacia el año 1480, sin que conozcamos dato alguno sobre su familia o sobre donde adquirió la sólida formación que le llevó a desempeñar puestos de responsabilidad en la administración castellana desde principios del siglo XVI. Lo cierto es que su periplo político-administrativo y su estatus religioso, le permitieron ocupar el obispado de Pamplona al final de su vida. Nombrado capellán de la reina Juana I de Castilla en 1508, fue mano derecha de Fernando II de Aragón (el Católico) y tras la conquista de Navarra, en su reestructuración administrativa, ejerció entre otras actividades como pagador de las obras y gastos extraordinarios de Navarra desde 1512 hasta su muerte. Como capellán de Carlos V sirvió en numerosos cometidos a la corona española. Las prebendas eclesiásticas de las que fue beneficiario y que tanto ansiaba fueron constantes a partir de 1523, ejerciendo como tesorero de la catedral de Pamplona entre 1530 y 1538. La anhelada mitra episcopal de la diócesis de Pamplona le llegó en la primavera de ese año de $1538^{8}$.

Por lo que respecta a las prescripciones dietéticas que nos ocupan, es necesario hacer notar el peso de la tradición medieval del galenismo árabe y latino respecto al baño y los masajes. Pese a la consideración del baño desde la perspectiva de la medicina preventiva en los tratados de higiene, el beneficio que de él esperaba el veneciano en 1524 es completamente curativo. Su planteamiento es claro y la propuesta es hacer uso de ellos antes de ingerir cualquier tipo de alimento, tanto a primera hora de la mañana como por la tarde antes de cenar, dejando un tiempo prudencial tras la comida del mediodía. La utilización del baño era percibida como una forma de sustituir el ejercicio o como medio de completar su acción ${ }^{9}$.

\footnotetext{
8. Goñi Gaztambide, José. Historia de los obispos de Pamplona, siglo XVI. Vol. III. Pamplona: Ediciones Universidad de Navarra-Gobierno de Navarra; 1985, p. 254-282. Un estudio actualizado sobre las biografías de Juan Rena y Juan de Alarcón, en Chocarro Huesa, Mercedes; Segura Urra, Félix. Inventario de la documentación de Rena. Archivo Real y General de Navarra. Pamplona: Gobierno de Navarra; 2013, p. 37-68 y 70-74.

9. Gil-Sotres, n. 3, p. 629
} 
Luis Lobera de Ávila, médico del emperador Carlos V, en su Banquete de nobles caballeros (1530) recogió algunos de los beneficios del baño, siglos antes recomendados por Rhazes ${ }^{10}$.

Rena tomaba los baños de cuerpo completo o tan solo de las partes afectadas, aunque por la mañana, antes de entrar en el baño, se propuso «vntar el hígado con vngüento sandalino e rosado, e cada mañana antes de vntar el hígado haré con un lienço linpiar lo que de la vnçión del día antes quedado oviere» ${ }^{11}$. Los problemas en las piernas - probablemente gota - y estomacales parece que fueron su principal calvario. Los largos periodos de baño - entre media y una hora- debían de aliviarle los dolores, y este tratamiento se completaba con friegas de orina caliente (cuyo origen no se especifica) y un ungüento también caliente. Por la tarde, una vez distribuido el ungüento, sus piernas tenían que enfundarse en lienzos templados debiendo acostarse una hora antes de cenar, mientras que por las mañanas no parece que se cubrieran sus piernas antes de ir a descansar. Estas prácticas, que se llevaron a cabo desde el 12 de mayo hasta que «no hiziese eçessivo calor», formaron parte de un tratamiento perfectamente regulado, en el que se incluían píldoras y ungüentos ${ }^{12}$.

En más de una ocasión el calor ambiental no se consideraba nada conveniente. De ahí que Rena afirme que si «hiziere de muncho calor haré poner sobre la vnçión del hígado vn lençezico delgado mojado en agoa rosada e vnas gotas de vinagre templado ${ }^{13}$. No resulta por tanto extraña la importancia otorgada a los medicamentos calientes y a la humedad aportada por los baños en las prescripciones destinadas a Juan Rena, habida cuenta de que en 1524, la fecha de su «regimiento» más temprano, podía rondar los 44 años de edad. Para la medicina del momento una persona llegaba a la vejez entre los 45 o 55 años, en función del grado en que para entonces habían disminuido las dos principales características complexionales de la persona y principios fundamentales de la vida: el calor natural y la humedad radical ${ }^{14}$. Disposiciones que vuelven a quedar vigentes cuatro años después, cuando fue atendido por los médicos Juan de Elizondo, médico

10. Lobera de Ávila, Luis. Banquete de nobles caballeros. Donostia/San Sebastián: R \& B Ediciones; 1996, p. 59.

11. Apéndice documental, n. ${ }^{\circ} 1$ [3].

12. Apéndice documental, n. 1 [7]. Las dos vísceras fundamentales que participan en la función digestiva son el estómago y el hígado (Gil-Sotres, n. 3, p. 738).

13. Apéndice documental, n. ${ }^{\circ}$ [3].

14. Gil-Sotres, n. 3, p. 845-846. 
de Pamplona y de los destronados reyes de Navarra, y Martín de Santacara, primer protomédico de Navarra ${ }^{15}$.

La estrecha relación de Juan Rena con Juan Vallés, nombrado protonotario y tesorero de Navarra en 1524 y 1528 respectivamente, ha quedado reflejada no solo en la relación epistolar conservada de la época en que Vallés estuvo en la corte al servicio de Carlos V entre 1519 y $1528^{16}$, sino también en una serie de recetas que éste le proporcionó para tratar sus problemas en una pierna. Las aficiones de Vallés por la medicina son bien conocidas ${ }^{17}$. No sería de extrañar que en una de sus obras médicas hoy desaparecida, las Flores de medicina y cirugía, se hubieran incluido algunas de las recetas que ofreció a Rena para la pierna:

«Tómese una cabeça de carnero y pélese y quebrántese y quítensele los sesos, y tanbién se tomen los pies y las manos y se pelen. Ítem se tomen rayzes de maluauisco dos libras, mancanilla, corona de rey y heneldo, de cada uno dos manojos, simiente de alholuas y de lino, entera la simiente, de cada uno media libra. Todas estas cosas cuezan en la quantidad de agua que fuere sufficiente y cuezan hasta que la carne de la cabeça y de las manos se aparte de los huesos. Y con este baño quanto más callente se pueda suffrir se laue

15. Apéndice documental, n. ${ }^{\circ} 2$ [10]. Sobre las actividades de los dos médicos aludidos, vinculados ambos a las élites navarras, véase Sánchez Álvarez, Julio. El Protomedicato navarro y las Cofradías sanitarias de San Cosme y San Damián. El control social de las profesiones sanitarias en Navarra (1496-1829). Pamplona: Gobierno de Navarra; 2010, p. 40-44 y 129-139. No es posible dilucidar la salud general de Juan Rena a lo largo de su vida, pero lo cierto es que a partir de su estancia en Navarra se conservan algunos listados de medicinas adquiridas. En junio de 1528 se tiene constancia de la compra de «exaropes, agoas cordiales, vna mededina laxatiba», por mandato de maestre Juan de Elizondo, «echa con decotión cordial y pectoral»; el 10 de septiembre «xaropes y agoas y vna medecina laxatiba para pugar a su merced (...) Ata XXVIII del dicho mes llebaron para su merced vnos julepes y vnas tabletas»; entre el 20 y el 24 de octubre se compraron distintos jarabes; el 28 «vna presa de píldoras por hordinació del doctor Sanctacara (...)»; el 30 «vn vngüento magistral» junto con otras medicinas; el 1 de noviembre «hun lectuario confortatibo hordenado por el doctor Sanctacara echo con polbos cordiales y otras diversas cosas (...)» tomados a Antonio de Caparroso. Las compras se prorrogaron hasta el 18 de marzo del año siguiente (AGN, Archivos Particulares-Rena, caj. 105, n. ${ }^{0}$ 15-3, fol. [1 r-2v]). Tal compra de medicamentos implica una 'crisis' de cierta importancia en la salud de Juan Rena, que muy bien pudo tener que ver con la redacción de la segunda prescripción dietética.

16. Véanse, por ejemplo, los documentos 7-1 y 7-2, caj. 87, de los Archivos Particulares-Rena, AGN.

17. Sobre la biografía de Juan Vallés y su actividad literaria, véase Serrano Larráyoz, Fernando. Juan Vallés (c.1496-1563): vida y obra (Regalo de la vida humana) de un humanista navarro de la primera mitad del siglo XVI. In: Serrano Larráyoz, Fernando, coord. [Juan Vallés] Regalo de la vida humana. Pamplona-Viena: Gobierno de Navarra-Österreichische Nationalbibliothek; 2008, p. 17-75. 
un ratico, y después de bañado y enxugado con un paño callente luego de presto se ponga el emplastro que está hecho y tenga siempre la pierna leuantada, digo tendida sobre alguna caxa. Este cozimiento se guarde para que en estos cinco o seys días se bañe con él cada día una vez o dos callentándolo siempre muy bien. Y los huessos se echen a mal por que se pueda lauar con las mesmas cosas que entran en el cocimiento» ${ }^{18}$.

La utilización de elementos farmacológicos, como píldoras, jarabes, tablillas y ungüentos se complementan con los alimentos y bebidas que el veneciano debía consumir en razón a su estatus social y a sus dolencias; un hecho que queda evidente tanto en el texto de 1524 como en el que se le prescribió hacia 1528. El número de comidas a realizar dependía de factores como la edad, la complexión, el estado de las fuerzas, el tiempo del año y la presencia o no de un cuadro morboso. Lo más propio para quienes tenían una complexión seca, acompañada de un fuerte calor innato y que acostumbraban a tomar alimentos exquisitos, era hacer dos comidas diarias $^{19}$. Las dos prescripciones consideraban que la comida y la cena eran de obligado cumplimiento. La primera establecía la hora de la comida en torno a las 10 de la mañana y la de la cena entre las 8 y las 9 de la noche, muy en consonancia con lo planteado por Arnau de Vilanova dos siglos antes ${ }^{20}$.

Respecto a los alimentos, la prescripción de 1528 de que el pan «sea hun día cozido» ${ }^{21}$ coincide con la propuesta de algunos regímenes medievales de no comer pan caliente ni aquel elaborado con más de dos días de antelación ${ }^{22}$. Tampoco menciona las legumbres, salvo los «garbanzos tostados» ${ }^{23}$, si bien algunos regímenes aceptan el consumo de habas, guisantes, judías y lentejas sobre todo cocidas, con la recomendación de no desaprovechar el caldo de su cocción por sus cualidades diuréticas y desobstructivas para las venas del cuerpo ${ }^{24}$. Cebollas y ajos, cocidos y asados, junto con hierbas aromáticas a las que se les atribuyen ciertas propiedades

18. AGN, Archivos Particulares-Rena, caj. 105, n. $17-2$. Otros remedios proporcionados por Juan Vallés para la misma dolencia, en AGN, Archivos Particulares-Rena, caj. 105, n.0 17-3. Se conserva también una «recebta del señor don Juan de Viamont», en cuyo verso se anota: «para la hijada» (hígado) (AGN, Archivos Particulares-Rena, caj. 105, n. ${ }^{\circ}$ 17-4).

19. Gil-Sotres, n. 3, p. 653-656.

20. Gil-Sotres, n. 3, p. 656-657.

21. Apéndice documental, n. ${ }^{\circ}$ [5].

22. Gil-Sotres, n. 3, p. 677.

23. Apéndice documental, n. ${ }^{\circ}$ [4].

24. Gil-Sotres, n. 3, p. 680-681. 
médicas, como la hierba santa, el hisopo y el perejil, formaban parte de las raíces consideradas apropiadas para combatir las dolencias ${ }^{25}$, aunque los tratados dietéticos no recomendaban consumirlas crudas ${ }^{26}$. En cuanto al resto de productos vegetales, la prescripción de 1524 no rechaza la ingesta de uvas pasas y almendras. Las uvas «sin granos» antes del plato principal («antepasto»), las segundas tostadas en la «sobremesa» de la comida. En la cena podían tomarse pasas y almendras con yemas de huevo frescas ${ }^{27}$. En la segunda prescripción dietética entre las frutas y frutos secos permitidos se incluían piñones, dátiles, higos (¿secos?), uvas pasas, almendras, avellanas y «nuezes moscadas en que sirua toda confitura, con que no sea calabacate o limones, y quando quisiere carne de membrillo sea con speçias» ${ }^{28}$. Disposiciones acordes con la negativa consideración de la fruta y las legumbres como alimento por parte de los médicos medievales y renacentistas y su valoración como medicamento, al igual que ocurría con las confituras -a base de azúcar o miel- y con las especias ${ }^{29}$.

Juan Rena propone caldo de pollo asado, de polla cocida o de carnero para comer el 14 de mayo de 1524. Dos días antes tenía previsto comer «yantar cozido», al día siguiente un caldo y «comeré como suelo», mientras que por la noche se obliga a cenar de «dieta» ${ }^{30}$. El texto de 1528 es más explícito. Se abandonan los caldos, aunque sigue parámetros similares a 1524 respecto a las variedades cárnicas: gallina «y su linage», perdigones, tórtolas, palominos caseros «y toda manera de aues del canpo o criadas, eçepto las de agoa y su natura, y sobre todo posarides gruesos y carnero (...) la mayor parte asado o en pasteles» ${ }^{31}$. De hecho la carne constituyó uno de los elementos principales de la alimentación medieval y renacentista, y se le atribuían virtudes medicinales, en especial a la volatería, considerada propia de las élites en el ideal alimentario. Sin embargo, los regímenes de salud rechazan todo tipo de aves acuáticas, tal y como se propone en el texto de $1528^{32}$.

25. Apéndice documental, n.० 2 [4].

26. Gil-Sotres, n. 3, p. 684.

27. Apéndice documental, n.o 1 [3].

28. Apéndice documental, n. 2 [4].

29. Gil-Sotres, n. 3, p. 687-688.

30. Apéndice documental, n.o $1[1,2$ y 3$]$.

31. Apéndice documental, n. ${ }^{\circ}$ [1].

32. Gil-Sotres, n. 3, p. 693. 
En lo referente al pescado, la diversidad de opiniones sobre su conveniencia o no es la tónica habitual del conjunto de los regímenes de salud medievales. El caso del autor de la dieta de 1528 para Juan Rena resulta más que evidente: «De pescados ningunos son buenos y quando hubiere de ser sea pescado fresco de vna cola o cangregos de río o cancros de la mar, o truchuelas muy frescas o yomejuelas, y desto pocas vezes» ${ }^{33}$. Tan escaso es el aprecio por este artículo que el propio Rena ni lo menciona en 1524. Algo similar sucede con la leche y los productos lácteos. La dieta de 1528 fija con claridad cuáles son los alimentos de los que debe prescindir: «todas cosas agres y verdes y de todo pescado, ecepto lo dicho, y de todas cosas saladas y carnes peliagudas y todas cosas de leche $(. ..) »^{34}$. Todo lo contrario sucede con los huevos. La parte más valorada es la yema y así queda constancia en el documento de 1524, cuando para el 12 de mayo Rena se propone cenar «yemas blandas», y dos días después «yemas frescas e passas e almendras». En 1528 las yemas frescas tenían que prepararse «asadas con açúcar y canela o echas en agoa de azar con açúcar y canela» 35 . La canela es la única especia destacada, aunque se permite tomarlas de todo tipo, incluyendo el azúcar - considerado entonces como especia- y la miel. No solo están indicadas para utilizarlas en artículos sólidos, como las yemas de huevo o en tostadas de pan mojadas con vino a la que se les añade diversas variedades («pólvora»), sino también en vinos dulces aguados «con agoa cozida con canela» ${ }^{36}$. Las virtudes medicinales de las especias, quedan reflejadas en los escritos médicos y su utilización dependía del tipo de enfermo dado el elevado precio de la mayoría de ellas ${ }^{37}$.

La única bebida a la que se alude es el vino, elemento fundamental de la dieta de la época junto con el pan. El vino aparece a la cabeza de los nutrientes recomendados, seguido por el jugo de carne y los huevos sorbidos. Las propiedades que le atribuían los regímenes de salud eran su capacidad para transportar el alimento a los miembros del cuerpo, su capacidad nutriente, la posibilidad de confortar el calor natural de los espíritus, facilitar la digestión, mejorar las evacuaciones y toda una serie

33. Apéndice documental, n. ${ }^{\circ}$ [2]. Sobre el pescado y su consideración en los regímenes de salud medievales, véase Gil-Sotres, n. 3, p. 695-699.

34. Apéndice documental, n. ${ }^{\circ}$ [7].

35. Apéndice documental, n. 1 [ 1 y 3]; n. 2 [3]. Sobre la consideración médica de los huevos, véase Gil-Sotres, n. 3, p. 699-701.

36. Apéndice documental, n. 2 [3, 5 y 6$]$.

37. Cruz Cruz, n. 2, p. 176-177. 
de acciones beneficiosas sobre el sistema nervioso central ${ }^{38}$. El vino propuesto en 1528 es el blanco «maduro olorioso y dulçe», aguado con agua cocida de canela, del mismo tipo de color que cuatro años antes propone Juan Rena para hacer una decocción con otros ingredientes ${ }^{39}$. Un vino -el blanco- considerado débil, que apaga la sed. Las características que se le atribuyen son positivas, ya que los vinos olorosos son capaces de nutrir al organismo y de «multiplicar los espíritus sutiles». Por su parte, los dulces son considerados ideales por su «extraordinario alimento, aunque suelen provocar mucha sed». Respecto a la necesidad de aguar los vinos las opiniones fueron discordantes según los médicos ${ }^{40}$.

El sueño y las emociones, incluidos respectivamente en las cosas no naturales cuarta y sexta, también quedan reflejados en estas prescripciones. Su carácter terapéutico se discierne en el texto de 1524. Juan Rena reconoce que tras la cena y unas friegas en los riñones con ungüento rosado es necesario dormir. Se intuye que la finalidad era reponerse del cansancio corporal ${ }^{41}$. Sobre las emociones la prescripción de 1528 le insta a «procurad muchos juegos y plazeres, y sea dos o tres oras después de aver çenado o comido, y el día que esto se hubiere de azer el comer sea mediado y no muy repleto» ${ }^{42}$. La alegría era el «accidente del alma» - alteraciones somáticas que se desencadenan al ritmo de las emociones, ocurridas a nivel del corazón- más valorado por los médicos siempre que tuviera un carácter moderado. El juego y el placer podían desencadenar esta alegría, con variados consejos para fomentarla, buscando evitar las preocupaciones ${ }^{43}$.

\section{Prescripciones dietéticas para Juan de Alarcón († 1551)}

Si resulta problemático fechar una de las prescripciones dietéticas destinada a Juan Rena, tanto o más difícil es hacerlo en el caso de las dirigidas a Juan de Alarcón, pues su redacción no recoge datación alguna. Una de ellas está

\footnotetext{
38. Gil-Sotres, n. 3, p. 717.

39. Apéndice documental, n. 2 [5] y n.० 1 [7].

40. Gil-Sotres, n. 3, p. 721 y $723-724$. Incluido en el tratamiento a seguir en 1528, se le prescribe tomar cada mañana, «en amaneçiendo», vino blanco tibio al que había que añadir una ochava de mitridato (Apéndice documental, n.० 2 [11]).

41. Sobre la higiene del sueño, véase Gil-Sotres, n. 3, p. 736-740.

42. Apéndice documental, n. ${ }^{\circ}$ [12].

43. Gil-Sotres, n. 3, p. 815-819.
} 
firmada por un tal doctor Medrano, del que consta sirvió en Pamplona al menos, entre 1541 y $1543^{44}$, aunque es muy posible que su actividad en la ciudad venga de años atrás. Se sabe que entre finales de agosto y principios de octubre de 1537 Alarcón compró diversas medicinas por un valor de 30 libras navarras, 3 sueldos y 8 dineros ${ }^{45}$. La prescripción del doctor Medrano, que he fechado en torno a 1538, es explícita en relación a los problemas hepáticos y estomacales de su paciente ${ }^{46}$.

De origen castellano, Juan de Alarcón aparece por primera vez en Navarra vinculado a la figura de Juan Rena, su señor, en la década de 1520-1530. Se convierte entonces en uno de sus hombres de confianza. Vivió en Pamplona, en la propia casa de Rena y de él aprendió el manejo de las tareas contables. Al marchar Juan Rena a la corte en 1529, le nombra apoderado para ejercer en su ausencia el cargo de pagador real de obras y gastos extraordinarios. Hasta la muerte de Juan Rena en 1539, Juan de Alarcón se ocupó además de administrar la casa y hacienda de su señor. Al fallecer Rena le sustituyó en el cargo de pagador hasta su muerte en 1551.

Al parecer las dolencias de Alarcón se prolongaron en el tiempo, puesto que se le propone hacer «exercicio en aiunas yugando a la pelota un rato ata que comience a sudar y otro tanto antes que cene y hacer exercicio moderado antes de comer y de cena, y no sobre comer ni cena hata que passen tres horas». Según Avicena, al aumentar el calor natural los materiales gruesos del interior del cuerpo se disolvían y, al mismo tiempo que se dilataban los poros, se facilitaba la salida de las superfluidades. Bernardo de Gordon resaltaba la importancia del ejercicio en el calor natural y su acción sobre el corazón, lo que activaba el sistema cardiorespiratorio y los sentidos del cuerpo (imaginación y memoria). De ahí que se pueda entender la receta de una epítima para el corazón en 1537. El fortalecimiento de los miembros es también una de las acciones del ejercicio, actividad que según las autoridades medievales y, como bien plantean los médicos navarros, debía ser moderada. El juego de pelota era uno de los más recomendables ${ }^{47}$. Cabe

44. En 1542 el doctor Medrano contaba con «quarenta y dos anos poco más o menos» (AGN, Tribunales Reales. Procesos, n. ${ }^{\circ} 130784$ (sin foliar)).

45. El 5 de agosto se compra «vn xarope conpuesto, echo con III onzas de reubarbaro y otras diversas cosas con su decotión muy copiosa en quantidat de IIII libras por hordinación del doctor Leggasa» (AGN, Archivos Particulares-Rena, caj. 105, n. ${ }^{\circ}$ 15-5).

46. Apéndice documental, n. ${ }^{\circ}$ [1].

47. Apéndice documental, n. 4 [5] y n. 3 [4]. Sobre el ejercicio en las autoridades médicas medievales, véase Gil-Sotres, n. 3, p. 601-625. 
preguntarse si los 'juegos' que se prescribieron a Juan Rena tuvieron que ver con la realización de ejercicio físico, principalmente por los problemas en la pierna de este último. Otro factor importante para logar la sanación de Alarcón fue la recomendación de alcanzar estabilidad emocional, apartándose «de toda tristeza y enojo», como se le instó también a Rena. Para lograr esta estabilidad se le exhorta a apartarse del «exercicio de las mugeres» y evitar la conversación con ellas, «porque a él le pesará» ${ }^{48}$. La tradición médica medieval consideraba la práctica sexual como necesaria para evitar enfermedades por su acción evacuadora, aunque se rechazaba para los enfermos ${ }^{49}$. Los daños que, a juicio de los contemporáneos, implicaba el coito también fueron expuestos por el citado Luis Lobera de Ávila ${ }^{50}$.

Las molestias estomacales de Juan de Alarcón quedan confirmadas también a través de la última prescripción. En ella se manda tomar cañafístula en caña (utilizada como purgante) y trementina de abeto (de propiedades balsámicas y diuréticas ${ }^{51}$. Una receta escrita por la misma mano le recomienda ingerir con la trementina ciertas píldoras y seguir el tratamiento:

«Tomará su mercet de quinze en quinze días dos píldoras de esas, vn poquito antes de cena et sunt sine custodia más que si no las tomasse. Y después al tercero día tome su trementina como ha acostumbrado, y en todo lo demás guarde su regimiento lo mejor que pudiere» ${ }^{52}$.

Por su parte, el tratamiento del doctor Medrano incluía tomar por las mañanas una tableta «de las que se ordenaron», acompañada de vino blanco con dos hojas de ajenjo amargo, y antes de comer especias mezcladas («polvora») o unas pocas grageas de canela y de anís. El ungüento rosado para los riñones que se recetó a Juan Rena se prescribe también a Alarcón, para aplicárselo por las tardes, si bien había que taparlo con un paño humedecido en agua rosada ${ }^{53}$.

La consideración sobre los alimentos beneficiosos y dañinos para el 'criado' de Juan Rena sigue los parámetros vistos en los regímenes destinados a su señor, si bien las variedades de cuadrúpedos descritas para Alarcón

\footnotetext{
48. Apéndice documental, n. ${ }^{4}$ [5] y n.० 3 [4].

49. Gil-Sotres, n. 3, p. 764 y 767.

50. Lobera de Ávila, n. 10, p. 57.

51. Apéndice documental, n. 4 [1].

52. AGN, Archivos Particulares-Rena, caj. 82, n.॰ 9-3.

53. Apéndice documental, n.० 3 [3] y n.० 4 [2].
} 
son algo más explícitas. Nada de leche, queso «ni carnes de pelagudo sino fuesse cabrito o de algún gazapo o ternera, haunque de la liebre puede comer el caldo» y carnero. El doctor Medrano le permitía el consumo de aves (sin especificar) y también carnero cocido por las mañanas para comer, todo ello sazonado con hierba santa y perejil, mientras que recomendaba alimentos asados para las tardes ${ }^{54}$. Por su buena digestión los tratados de salud medievales recomendaban la carne de cabrito, ternera, conejo, aunque de este último no recomendaban que fuera asado ${ }^{55}$. La variedad de aves permitidas en la primera prescripción es amplia pero, en líneas generales, no hay diferencias sustanciales con los principios aludidos en las propuestas para Juan Rena: gallinas «o su linage», perdices, codornices y «todo linage de aues saluo ánades y ánsares» ${ }^{56}$. Tampoco sorprende la recomendación de Medrano a su cliente de hacerle «buscar un poco de hígado de lobo y yo le diré que a de hazer para su salud», porque incluso en la medicina culta de la época no estaban desterradas del todo algunas consideraciones simbólicas propias de la magia simpática ${ }^{57}$.

Los alimentos salados y agrios, las berzas, los rábanos, las legumbres, salvo el caldo de garbanzos, «el qual deue mucho usar», son desaconsejados en las prescripciones dietéticas ${ }^{58}$. Si la dieta destinada a Juan Rena en 1528 permitía la ingesta de cebollas y ajos asados, en el documento más reciente destinado para Alarcón se considera de alguna utilidad la cocción de hojas de rábanos, acelgas, borrajas y ortigas «con su perrexil» ${ }^{59}$. Variedades que, en general, eran utilizadas para tratar algunas afecciones intestinales ${ }^{60}$. Una vez más se comprueba el recelo de los médicos hacia las hortalizas. Igualmente

\footnotetext{
54. Apéndice documental, n.० 4 [3] y n.० 3 [4].

55. Gil-Sotres, n. 3, p. 691-692.

56. Apéndice documental, n. ${ }^{4}$ [4]. Como en el caso de Juan Rena hay un rechazo absoluto por parte de los médicos, como sucede en el periodo medieval, a las aves acuáticas migratorias. Los regímenes medievales consideran a las aves menos nutritivas que los cuadrúpedos, pero eran más digestibles, por lo que los médicos primaron su consumo (Gil-Sotres, n. 3, p. 693-694).

57. Apéndice documental, n.० 3 [5].

58. Apéndice documental, n. 3 [4] y 4 [3]. El doctor Medrano considera impropio el consumo de todo tipo de legumbres (Apéndice documental, n. 3 [4]). Incuso el arroz, producto de cierto lujo a finales del medievo y principios del Renacimiento tampoco es considerado óptimo para curar a Juan de Alarcón (Apéndice documental, n.o 4 [3]).

59. Apéndice documental, n.o 4 [4]. Según Arnau de Vilanova el caldo de las legumbres abre y limpia las venas capilares del hígado, y las vías urinarias, siendo un buen remedio contra los cálculos, sobre todo si al caldo se le añade perejil (Gil-Sotres, n. 3, p. 681).

60. Gil-Sotres, n. 3, p. 683.
} 
la fruta fresca fue proscrita en ambas dietas, haciéndose hincapié en la segunda de ellas, de la inconveniencia de la uva fresca, pese a ser una de las variedades más utilizadas como laxante. Entre los frutos secos las castañas son despreciadas, pero se aceptaban las pasas, las almendras - pudiéndose elaborar con ellas un potaje llamado almendrada - y los piñones ${ }^{61}$.

El pescado, como sucede con las prescripciones dietéticas para Juan Rena, estaba poco considerado, con la excepción de alguna trucha o madrilla ${ }^{62}$. Al igual los huevos - frescos y «blandos»-gozaban de buena consideración ${ }^{63}$. El texto de 1538 aprueba el consumo de «alguna manteca fresca» ${ }^{64}$, pese a que por regla general la leche y sus derivados con algunas salvedades no se consideraban alimentos adecuados. El mismo texto recomienda no beber «agua cruda» ${ }^{65}$, por la facilidad con que se corrompían las aguas de pozos, lagos, lagunas y estanques. Para hacerla bebible, según los médicos, había que hervirla, echarle vinagre y ventilarla varias veces cambiándola de recipientes ${ }^{66}$. Respecto al vino, si en las prescripciones para Rena se aconsejaba fuera blanco «maduro» y aguado con agua cocida de canela, a Juan Alarcón el doctor Medrano le propone tomar «vino blanco muy bueno serenado de por noche con dos o tres oijas de acensones amargas machacadas puestas dentro», de gran beneficio pese a su sabor amargo, y vino blanco o tinto «claro maduro, amesado medianamente». En la dieta más reciente se sugiere beber vino blanco bien aguado. Ambos documentos sugieren mesura en el beber durante las comidas e implícitamente, no comer ni beber entre horas. De ahí el consejo del doctor Medrano a Juan de Alarcón de que no «haga collaciones» ${ }^{67}$, para no castigar en demasía su delicado estómago.

La frugalidad en la bebida había de acompañarse con la costumbre de no dormir durante el día, «y menos sobre comer y ni cena», es decir después de

\footnotetext{
61. Apéndice documental, n. ${ }^{\circ} 3$ [4] y n.० 4 [3 y 4].

62. Apéndice documental, n. 3 [4] y n. 4 [4]. La trucha también aparece mencionada en la dieta de 1528 destinada a Juan Rena.

63. Apéndice documental, n. ${ }^{\circ}$ [4] y n.० 4 [4].

64. Apéndice documental, n. 3 [4].

65. Apéndice documental, n. 3 [4].

66. Bau, Andrea María; Canavese, Gabriela Fernanda. «Agua que cura, agua que alimenta». La dietética para sanos y el uso del agua en la sociedad española bajomedieval y moderna. Cuadernos de Historia de España. 2006; 80: 127-146 (136).

67. Apéndice documental, n. 3 [2 y 4] y n.० 4 [5]. La tradición médica medieval desaconsejaba beber en ayunas (Gil-Sotres, n. 3, p. 726).
} 
las ingestas más importantes ${ }^{68}$. Era necesario esperar a que la materia que había de convertirse en sustancia del organismo se encontrara localizada en un lugar conveniente para su transformación. Recomendaciones dirigidas a valorar negativamente la siesta o sueño de primeras horas de la tarde ${ }^{69}$.

Las friegas en los riñones con ungüento rosado que debían aplicarse a Juan Rena en 1524 y el consejo a Juan de Alarcón en la última de las prescripciones de no llevar «demasiada ropa sobre los riñones» ${ }^{70}$, tienen su origen en la idea de que las «superficialidades de la segunda digestión se eliminan a través de los riñones, que actúan a modo de filtro, separando de los líquidos lo inútil, lo que no puede ser aprovechado por el organismo» ${ }^{71}$. Ambas disposiciones iban encaminadas a facilitar el buen funcionamiento de sus órganos. Del mismo modo la indicación a dicho Alarcón de que no retuviera «mucho la orina» va en la misma dirección, puesto que tras el sueño, una vez completadas la segunda y tercera digestión, la vejiga llena tenía que ser vaciada, y lo mismo durante el resto del día, tantas veces como fuera necesario.

\section{Reflexiones finales}

Además de reflejar un género textual poco conocido para la España del siglo XVI, los documentos que presentamos resultan significativos para llegar a conocer la práctica real de los postulados teóricos de la medicina universitaria y del galenismo en personajes concretos. Son textos de difícil clasificación en categorías inevitablemente ficticias, pero que muestran el esfuerzo de médicos y pacientes por adaptar e individualizar los conocimientos propios de los manuales especializados en el mantenimiento de la salud. Ofrecen así una visión plenamente personalizada de la enfermedad y su tratamiento, que sirve de contrapunto a la homogeneización y a las generalizaciones de los regímenes de sanidad difundidos por la imprenta durante el Renacimiento. Pese a las diferencias que pueden observarse en las recomendaciones para Juan Rena y Juan de Alarcón, existen toda una serie de coincidencias de carácter práctico. Las similares variedades de

\footnotetext{
68. Apéndice documental, n. 4 [5].

69. Sobre estas cuestiones, véase Gil-Sotres, n. 3, p. 740-743.

70. Apéndice documental, n. 4 [5].

71. Gil-Sotres, n. 3, p. 756.
} 
carnes que se recomiendan, el recelo a las verduras, legumbres, tubérculos y fruta fresca junto con la poca consideración que se tiene por el pescado, salvo algunas excepciones, al igual que sucede con la leche y sus derivados, o la búsqueda de los placeres de la vida y la felicidad, con la excepción de la práctica del sexo, son algunos ejemplos.

Se debe poner de manifiesto el valor que estos textos debieron de tener para sus dueños. Uno de ellos, el más antiguo, fue redactado por el propio enfermo, Juan Rena, lo que muestra la implicación del propio paciente. Es significativo también que la lengua de estas prescripciones sea el castellano en vez del latín, particularidad nada desdeñable cuando se trata de prescripciones realizadas por médicos cultos para personajes que conocían bien la lengua latina y que deja constancia de la importancia que han adquirido las lenguas vulgares en la trasmisión de los conocimientos médicos entre las propias élites ilustradas.

Por último, por lo que respecta a la tradición médica ofrecida por los originales estudiados, se evidencia una perfecta trasposición de lo recomendado en los tratados médicos doctrinales al mundo de la práctica. Los planteamientos medievales continuaron vigentes. Así, el recurso a los principios alopáticos para combatir enfermedades y la alimentación de los enfermos con dietas contrarias a las cualidades complexionales propias del cuadro morboso quedan plenamente reflejados en los ejemplos particulares de Juan Rena y Juan de Alarcón.

\section{Agradecimientos}

Quisiera agradecer a Montserrat Cabré i Pairet, Jon Arrizabalaga Valbuena, Lluís Cifuentes i Comamala, Juan Jesús Virto Ibáñez, Carmen Sánchez Téllez, Félix Segura Urra, Itzíar Zabalza Aldave y a los dos evaluadores anónimos por sus comentarios y precisiones al texto original. 


\section{APÉNDICE DOCUMENTAL}

1524, mayo 11

Prescripciones dietéticas de [Juan Rena] para seguir a partir del 12 de mayo de 1524

Archivo General de Navarra, Archivos Particulares-Rena, caj. 105, n. ${ }^{\circ}$ 17-7

1r/ [1] El jueues en la noche tomeré antes de çenar dos píldolas de 12 granos cada una; abré comido al yantar cozido y ceneré entre las 8 y 9 vna (sic) yemas blandas.

[2] El viernes tomeré 1 caldo $\mathrm{y}^{72}$ comeré como suelo. A la noche çeneré de dieta.

[3] El sábado tomeré 1 bano (sic) a las 6 y staré en él vna ora; salido dél me laueré los pies con vrinas calientes y me yré a la cama en la qual staré dos oras. Comeré a las 10 [çumo] de vn pollo assado e de polla cozida o vn poco de çumo de carnero. Por antepasto passas sin granos. Sobremesa almendras tostas.

A las siete de la tarde tornaré al baño por media hora e después lavaré los pies con las vrinas e después de linpios de la humedad me haré vntar con la vnçión caliente e enboluerán los pies en vnos lienços tenplados, e estaré vna hora sin çenar en la cama.

Haré la çena de vnas yemas frescas e passas e almendras y vna hora después me vntarán los reñones con vngüento rosado e después dormiré.

A la mañana antes de entrar en el bano me haré vntar el hígado con vngüento sandalino e rosado, e cada mañana antes de vntar el hígado haré con un lienço linpiar lo que de la vnçión del día antes quedado oviere.

Si días hiziere de muncho calor haré poner sobre la vnçión del hígado vn lençezico delgado mojado en agua rosada e vnas gotas de vinagre templado.

1v/ Abiendo vsado el baño quatro días desta manera al quinto tomaré vna píldora de la massa que queda, la quoal pese quinze granos; digo que la tomaré martes en la noche e el miércoles no haré baño fasta la noche ante de çena.

[4] Jueues e los tres días siguientes me haré bañar como antes, e domingo en la noche tomaré otra píldora e lunes no me bañaré fasta la noche.

[5] El martes siguiente haré tomar vna onça del vngüento e añedirle peso de ocho granos de poluo de euforbio, e salido del baño de esa mañana e linpio de la humedad de las

72. 1 caldo y] Ms. subrayado. 
vrinas me haré vntar los pies con esta vnçión caliente e la tendré por dos horas, e después me haré linpiar della los pies para me levantar, e a la noche dexarela toda la noche.

[6] El viernes añediré a lo que del vngüento quedare a vna onça doze granos de euforbio e con este vngüento me vntaré los días que restare de baño.

[7] Después que me dexaré de bañar me haré cada mañana por quatro días poner vn paño de agua ardiente que sea buena en cada pie por vna hora, el qual paño se tienple entre las manos. De quatro en quatro días vsaré vna píldora ante çena mientra no hiziese eçessivo calor.

2r/ Pondrán para cada decoçión vn cántaro de vino blanco e otro de agua de ferreros e vn açumbre de vinagre, e de las yerbas la quantidad que señale de cada vna Ivn puno $(\operatorname{sic})^{73} /$, e de rosas e granos de arraihán de cada vno dos puños. Lo que pondrán para cozer es los granos de arraihán e cozerá ochavo de hora e luego las hojas de laurel, e como vn buen fervor ayan passado echen todas las otras yerbas eçepto la mançanilla e melliloto, que se pondrán al vltimo fervor, e las rosas que se han de poner quitando la caldera del fuego basta que mengue este cozimiento el vn terçio e queden los dos terçios.

En lugar de saluia pondrán ruda con lombrizes \vna dozena ${ }^{74} /$. Haziendo tienpo tenplado durará cada decoçión para quatro ${ }^{75}$ dias, y si muncho calor hiziere se renovará pasados tres días.

\section{Recepta del ungüento ${ }^{76}$}

Olei antiqui, olei yrini, ana uncias v.

Opoponaci, galbani, bdeli, storacis, ana uncias semis.

Resolutis gumarum ${ }^{77}$ in vino con cera alba.

Fiat unguentum.

Evforbium, sicut supra dictum est.

2v/ A XI de mayo 1524

16875

Martes 26 de abril empecé a tomar los banos.

\footnotetext{
73. un puno] Ms. interlineado.

74. vna dozena] Ms. interlineado.

75. tres] Ms. tachado.

76. Recepta del ungüento] Ms. subrayado.

77. gumarum] Ms. gunarum, interlineado sobre gumas, tachado.
} 
[1528]

\section{Prescripciones dietéticas destinadas a Juan Rena}

Archivo General de Navarra, Archivos Particulares-Rena, caj. 105, n. ${ }^{\circ}$ 17-5

[1r]/ El regimiento que el señor micer Joan a de tener es lo seguiente:

[1] Primeramente quanto a las carnes comerá galina y su linage, perdigón, tórtolas, palominos caseros y toda manera de aues del canpo ${ }^{78}$ o criadas, eçepto las de agoa y su natura, y sobre todo posarides gruesos y carnero, y esto sea de la manera que su merçé mandare, pero la mayor parte asado o en pasteles.

[2] De pescados ningunos son buenos y quando hubiere de ser sea pescado fresco de vna cola o cangregos de río o cancros de la mar, o truchuelas muy frescas o yomejuelas, y desto pocas vezes.

[3] Yemas de huebos frescas, asadas con açúcar y canela o echas en agoa de azar con acúcar y canela.

[4] De las frutas piñones y dátiles, higos y pasas, garbanços tostados, almendras y abelanas, nuezes moscadas en que sirua toda confitura, con que no sea calabacate o limones, y quando quisiere carne de membrillo sea con speçias. Puede comer cebolas cozidas y asadas y ajos cozidos o asados e hierbasanta, ysopo y perexil.

[5] Todas espeçias coma y miel, el pan sea de hun día cozido, el bino sea blanco maduro olorioso y dulçe, agoado tenpradamente con agoa cozida con canela.

[1v]/ [6] Tomareys por sobre comer y çenar vna tostada muy delgada mojada en vino que bebeys puro, y sacado del binno cargarle a de ambas partes de la póluora y comerlaeys, y después de comida no bebaes nenguna cosa.

[7] Guoardaos de todas cosas agres y verdes y de todo pescado, ecepto lo dicho, y de todas cosas saladas y carnes peliagudas y todas cosas de leche, y de agoa cruda andad muy aropado y mucho secando a las pies y a la cabeça. Procúrese en todo caso mucho plazer e euítese de todos enojos.

[8] Las cosas señor que abeys de azer de medeçinas son las siguientes: en el quarto postrero desta luna. Ocho días antes tomad tres maynanas y tres noches los xarabes que quedan ordenados y la tablila primero d'eyllos. Después, al quarto día, tomad las siete pilloras que quedan ordenadas y ese día se se xiga como las que se purguan.

78. salua] Ms. tachado. 
[9] Después de purgado nuebe días aseo, tomad la tablila que queda ordenada y beber sobre ello hun trago de vino primero o agoa de asençios.

[10] Después desto echo cumplido cada noche vos huntad las caderas y el petineon con esta huntura, la mano bien caliente y después denbebido el vnguinte ponga hun paño caliente, y esto se aga dentro en la cama bien caliente y abrigado

[11] Tome agora cada maynana vna ochaua de metridato desecho en vino blanco tibio en amaneçiendo.

[2r]/ [12] Quoando quisieredes ${ }^{79}$ antes, procurad muchos juegos y plazeres, y sea dos o tres oras después de aver çenado o comido, y el día que esto se hubiere de azer el comer sea mediado y no muy repleto.

$[2 \mathrm{v}] /[$ en blanco $]$

\section{$[3 r] /$ Jesuchristo}

[Columna $\mathrm{A}]$ / Clabos de girofre, nuezes mozcadas, ginginbre blanquo, zedoari, graringal, pebre longo, pebre redondo, granos de genebro, scorçio de citrón, scorcio de toronjas, flor de salbia, basili, flor de romero, ençens masclo, aloe, exatic, menta redonda, grana de laurel ${ }^{80}$.

[Columna B] / Poleo, regal, genciana, calamenti, flor de sabico, rosas blanquas, ameos, spicanardi, cunbebas doméstiquas, cardamoni, magna, calami aromatiçi, camapiteos, semiente de nigela, maçis, flor d'abet, semiente de artamisa.

De todo lo susodicho sendas dragmas con sus escriptos cada uno en su paperico.

Anbre gris, roybarbo, romero, ruda, salbia, tomillo, poleo y picon sendas dragmas otras cada uno por sí con su scripto, y si todo lo susodicho es doblado ya es muy mejor.

79. I] Ms. tachado.

80. ossis de corde çerbi yo tengo] Ms. entre columnas. 


\section{Prescripciones dietéticas destinadas a Juan de Alarcón}

Archivo General de Navarra, Archivos Particulares-Rena, caj. 82, n. ${ }^{\circ} 9-1$

[1] El señor Alarcón tiene vna complexión muy regalada y delicada porque tiene el hígado algo flaco en virtud y el sthómago húmedo y el vaço muy ventoso y la digestión primera y segunda débiles y tardías, y para esto a my me paresce que será bien que continúe para el reparo de su sthómago a traer sobre él el talengoncito que le ordoné bien faxado.

[2] Ítem que tome cada mañana mientras durare una tableta ${ }^{81}$ de las que se ordenaron con vn trago o dos de vino blanco muy bueno serenado de por de noche con dos o tres oijas de acensones amargos machucadas puestas drentro, porque aunque al tomar del dicho vino le paresca amargo serle a muy probechoso.

[3] Ítem tomará sobre comer o de la pólbora que tiene o de vna poca de dragea de canela y de anís hechan.

[4] Ítem hará exercicio en aiunas yugando a la pelota un rato ata que comience a sudar y otro tanto antes que cene. Coma de su ave y carnero cozido en las mañanas con ierbasancta y perexil y assado en las tardes. Beba buen vino blanco o tinto claro maduro, amesado medianamente. $\mathrm{No}^{82}$ beba agua cruda, no coma fruta cruda ny coma cosa agre ny salada ny pelaguda, ny legumina ny pescado sino fuese de alguna truncha. Coma algunos huebos frescos y de alguna manteca fresca. No duerma entre día ni haga collaciones, beba poco a sus comeres, quítese de enojos y tome quanto plazer pudiere excepto que no conversse con mugeres porque a él le pesará.

[5] Haga buscar un poco de hígado de lobo y yo le diré lo que a de hazer para su salud, y con tanto Dios le tenga de su mano y quedo a su seruicio.

Doctor Medrano (rubricado).

81. que] Ms. tachado.

82. con] Ms. tachado. 
[1539/1540-1551]

Prescripciones dietéticas destinadas a Juan de Alarcón

Archivo General de Navarra, Archivos Particulares-Rena, caj. 82, n. ${ }^{\circ}$ 9-2

Jesucristo, María

[1] Lo que al señor Alarcón conuiene es que esté vn mes continuo cada semana vna vez de tomar de mañana a las VI horas vna onca de cañafístula en caña li[...] y chupando la pulpa de dentro, y desque la aya tomado tome detrás cuarto vna almendra de ${ }^{83}$ trementina de abet que sea muy buena y después no duerma, y passada vna hora o dos se podrá llebantar, y no coma \después de tomado esto/ ${ }^{84}$ hasta las XI horas ni salga de casa hasta después de comer, y así lo continuará esto como está dicho:

[2] Item se haga traer dos oncas de vnguiento rosado y con él le vntarán cada ${ }^{85}$ tarde vna vez todos los riñones detrás y encima le pernan vn paño mojado en agua rosada, y de mañana no se vnte.

[3] Et haziendo esto \y después/ ${ }^{86}$ es menester que se guarde de comer leche ni queso ni carnes de pelagudo si no fuesse cabrito o de algún gaçapo o ternera, haunque de la $^{87}$ liebre puede comer el caldo, ni coma cosas saladas ni agres, ni vercas ni castañas ni ráuano, sino las hojas, y legumina si no fuesse caldo de garbancos, el qual deue mucho usar, ni coma pescado de mar $\backslash$ ni enguilas $/{ }^{88}$, ni fruta y menos ubas, no coma roz.

[4] Deue comer gallina o su linage, carnero o perdiz o codornizes y todo linage de aues saluo ánades y ansares. Puede comer guebos frescos y blandos y de alguna trucha o madrilla, de algún caldo de garbancos y alguna almendrada o de algunas acelgas y borraynas y ortigas cozidas con su perrexil. Puede comer pasas y almendras y piñones.

[5] No beua ${ }^{89}$ sino al comer, y entonces su buen vino blanco bien aguado, no duerma entre día y menos sobre comer ni cena. Procure de hacer exercicio moderado antes de comer y de cena, y no sobre comer ni cena hata que passen tres horas, e sobre todo guarde el exercicio de las mugeres, especialmente sobre comer. Aparte de sí de toda tristeza y enojo y no trayga demasiada ropa sobre los riñones ni retenga mucho la orina.

\footnotetext{
83. Ms. tachado ilegible.

84. de tomado esto] Ms. interlineado.

85. da] Ms. repetido y tachado.

86. y después] Ms. interlineado.

87. lib] Ms. tachado.

88. ni enguilas] Ms. interlineado.

89. b]Ms. tachado.
} 